Article

\title{
Evaluation of the Resilient Modulus of Hot-Mix Asphalt Made with Recycled Concrete Aggregates from Construction and Demolition Waste
}

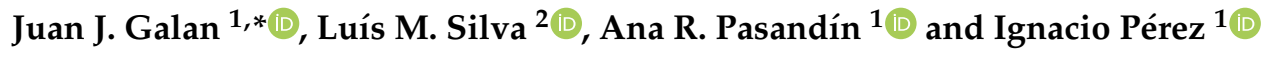 \\ 1 ETSI Caminos, Canales y Puertos, University of A Coruña, Campus de Elviña s/n, 15071 La Coruña, Spain; \\ arodriguezpa@udc.es (A.R.P.); ignacio.perez1@udc.es (I.P.) \\ 2 CIETI, ISEP-School of Engineering, Polytechnic of Porto, Rua Dr. António Bernardino de Almeida 431, \\ 4249-015 Porto, Portugal; lms@isep.ipp.pt \\ * Correspondence: jgalan@udc.es
}

Received: 3 September 2020; Accepted: 13 October 2020; Published: 16 October 2020

check for updates

\begin{abstract}
This paper reports the influence of the percentage of recycled aggregate (RCA) from construction and demolition waste (C\&DW) together with the percentage of binder $(\mathrm{L})$, curing time $(t)$ and temperature $(T)$ of the samples on the stiffness of a hot asphalt mixture. The study was carried out using the response surface methodology (RSM). The resilient modulus was chosen to estimate the stiffness of the mixture. The percentages of RCA studied were $0 \%$ (control), $5 \%, 10 \%, 20 \%$ and $30 \%$, whilst $3.5 \%, 4 \%$ and $4.5 \%$ were those chosen for the binder content. Before compacting the samples, they were left into the oven to cure. Curing time, or pretreatment time, were set at 0 (control), 2 and $4 \mathrm{~h}$. The samples were subjected to temperatures of 0,10 and $20^{\circ} \mathrm{C}$. The natural aggregate is of the hornfels type. All the specimens studied showed high stiffness at low temperatures. According to this research, temperature proved to be the most influential factor on the decrease in the resilient modulus and, conversely, the percentage of recycled aggregate is not a significant factor in the range of values studied.
\end{abstract}

Keywords: recycled concrete aggregate; construction and demolition waste; resilient modulus; hot-mix asphalt; response surface methodology

\section{Introduction}

According to the basis of circular economy, materials and products must be kept in use as long as possible in order to generate a sustainable European economic framework [1]. Recycling of construction and demolition waste is one of the mandatory aims of the European Union. The European commission itself states the following: "The Commission will take a series of actions to ensure recovery of valuable resources and adequate waste management in the construction and demolition sector and to facilitate assessment of the environmental performance of buildings" [1].

The partial or total replacement of natural aggregates by recycled ones from construction and demolition waste (C\&DW) as recycled aggregate in the manufacture of road pavements could constitute a real possibility to reuse this kind of waste $[2,3]$.

The use of $C \& D$ as a partial aggregate in hot bituminous mixes contributes to the reuse of construction and demolition waste. This reduces the energy consumption that would be necessary to dispose of this waste in a conventional way. For example, it is estimated that the waste industry in Great Britain emits around 250.3 $\mathrm{Mt}$ of $\mathrm{CO}_{2}$ per year. [4].

According to Chappat et al., [5], a sustainable pavement is "A safe efficient and environmentally-friendly pavement which meets the needs of present-day users without compromising those future generations", 
for this purpose a sustainable pavement must optimize the use of natural resources and reduce the energy consumption in order to reduce the greenhouse emissions. All this must be achieved without reducing the comfort and safety of users. Several environmental studies found that the use of recycled aggregates reduces energy use and emissions $[6,7]$.

Many of the road pavements, both in Europe and America, are made with hot-mix asphalt (HMA). In this type of mixture, the aggregates represent around of $95 \%$ in weight. Therefore, using a recycled aggregate, such as C\&DW, instead of natural ones, not only helps to reuse the waste, but also to save natural resources. In addition to that, according to Saberian et al., the recycling of C\&DW contributes to reducing the carbon emissions by around 65\% [8]. In addition, the construction of pavements using C\&DW not only contributes to the profitability of CD\&W, but also to preserve natural resources. Therefore, the use of $C \& D W$ as a recycled material can be considered a viable and sustainable option.

In this regard, mention should be made to the works of Aljassar et al., on the use of C\&D in hot-mix asphalt in Kwait [9], Paranavithana and Mohajerani report that hot-mix asphalt made with C\&D shows a mechanical behavior similar to the conventional ones [10]. Two of the authors of the present paper, Pérez and Rodríguez Pasandín, designed a hot-mix asphalt for flexible sections of pavements for medium or low volumes of traffic. They had a performance comparable to the conventional HMA [11].

\section{Aim and Scope Definition}

The goal of this research was to estimate the influence of the percentage of recycled aggregate from C\&DW (\%RCA), temperature (T), curing time $(t)$ and the percentage of the binder $(\% \mathrm{~L})$, as well as the mutual influence between them on the stiffness of HMA.

Several metrics can be chosen for measuring the stiffness, such as complex modulus, dynamic modulus, or resilient modulus [12]. The latter was chosen for the present work.

The type of the mixture studied was an AC22 base 50/70 G. In Spain, this nomenclature means the following: An asphalt concrete mixture with a nominal maximum grain size of $22 \mathrm{~mm}$ used in base courses in road pavements with 50/70 bitumen penetration and with a coarse gradation (G). This mixture was chosen because less requirements are demanded according to the Spanish specifications [13].

A composite factorial design was implemented after conducting several laboratory tests in order to obtain a nonlinear regression model that makes it possible to determine the optimum level of the parameters mentioned above.

\section{Materials and Methods}

In a previous piece of research, the mechanical properties, such as the indirect tensile strength (ITS) and the effect of the water on cohesion (stripping) (ITSR) of a HMA manufactured with several percentages of C\&DW as recycled aggregate were studied [14]. In the present paper, the resilient modulus was estimated to evaluate the stiffness of the mixture.

It is well known that the bituminous mixtures are not an elastic material, but instead they present a certain permanent deformation after each application of the load [15]. However, if the applied load is small compared to the strength of the material and is repeated for a sufficient number of cycles, the deformation that occurs under each load application is practically recoverable and proportional to the load. Therefore, the bituminous mixtures can be considered as viscoelastic material. The modulus of rigidity obtained, when the ratio between the deviator stress and the recoverable strain of a bituminous mixture remains constant after repetitive loads, is called the resilient modulus, MR.

The samples, the object of this study, were made using different percentages of recycled aggregate from C\&DW: $0 \%$ (control), $5 \%, 10 \%, 20 \%$ and $30 \%$. Before the specimens were compacted, they were left in the oven. Through this process, curing or pretreatment time, the aggregate will better absorb the bitumen. They are pretreated for 0 (control), 2 and $4 \mathrm{~h}$ in the stove. The experiment was carried out at three temperatures: 0,10 and $20^{\circ} \mathrm{C}$. 
The response surface methodology (RSM) was used to estimate the influence of the factors and interactions between them on the response variable. In order to obtain the maximum information at the cost of a limited number of experiments, a design of experiments was drawn. This methodology has been applied in a previous paper [14] and for other authors [16-19].

\subsection{Materials}

\subsubsection{Natural Aggregates}

Hornfels were used as a natural aggregate. This aggregate is normally used to produce HMA in Spain. According to $\mathrm{X}$-ray fluorescence analysis, its main component is $\mathrm{SiO}_{2}(62.3 \%)$. It was supplied by a local contractor and it complies with Spanish specifications for roads, PG-3 [20].

Table 1 shows the properties of the natural aggregate, where $L A$ is the Los Angeles abrasion coefficient, $W A$ is the water absorption, $F P$ is the fracture particles, $\rho$ is the bulk specific gravity, $S E$ is the sand equivalent and $F I$ is the flakiness index.

Table 1. Characterization of the natural aggregate.

\begin{tabular}{ccccccccccc}
\hline \multicolumn{10}{c}{ Fraction } \\
\hline Test & Standard & PG-3 & $\mathbf{0 / 2}$ & $\mathbf{2 / 4}$ & $\mathbf{4} / \mathbf{6 . 3}$ & $\mathbf{5 / 6 . 3}$ & $\mathbf{4 / 8}$ & $\mathbf{6 . 3 / 1 2 . 5}$ & $\mathbf{1 0 / 1 6}$ & $\mathbf{1 6 / 3 1 . 5}$ \\
\hline LA (\%) & EN-1097-2 & $<25$ & - & - & - & - & - & - & - & 14.2 \\
WA (\%) & EN-1097-6 & - & 0.79 & 1.67 & 1.25 & - & 1.08 & 0.92 & 0.60 & 0.62 \\
FP (\%) & EN-933-5 & 100 & 100 & 100 & 100 & - & 100 & 100 & 100 & 100 \\
$\rho\left(\mathrm{g} / \mathrm{cm}^{3}\right)$ & EN-1097-6 & - & 2.74 & 2.78 & 2.78 & & 2.79 & 2.79 & 2.77 & 2.79 \\
SE (\%) & EN-933-8 & $>50$ & 61 & - & - & - & - & - & - & - \\
FI (\%) & EN-933-3 & $<35$ & - & - & - & 24 & - & - & - & - \\
\hline
\end{tabular}

\subsubsection{Recycled Aggregates (RCA)}

Construction and demolition waste $(C \& D W)$ were used as recycled aggregate (RCA) for manufacturing HMA. Previously, before using it, the RCA was crushed, washed, pollutant was removed, and it was sieved at the C\&DW plant waste. The C\&DW plant produces fractions of $0 / 40 \mathrm{~mm}$. Figure 1 shows the gradation curve provided by the plant.

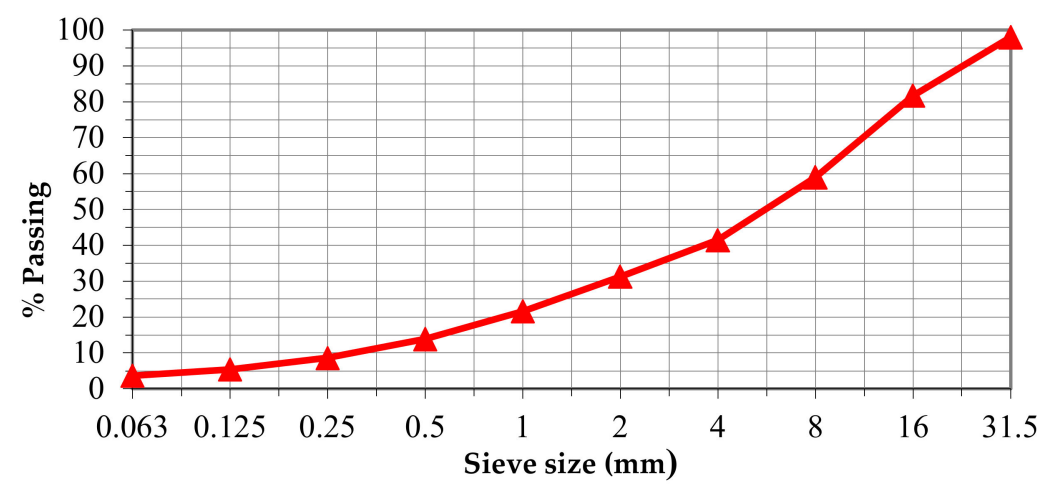

Figure 1. Gradation curve of recycled aggregate (RCA).

It can be seen in the graph that the fraction $0 / 40 \mathrm{~mm}$ has a continuous gradation, hence any fraction of RCA can be used to manufacture the HMA. In this work, only coarse RCA ( $>4 \mathrm{~mm}$ ) was used for HMA manufacturing.

The composition of RCA in weight can be seen in Figure 2. It shows that the components in greater proportion are concrete and stone. The characteristics of RCA are displayed in Table 2. Both the flakiness index and sand equivalent meet the Spanish requirements. However, RCA does not comply 
with Los Angeles' abrasion coefficient specification, for this reason the mix will not be designed for the wearing course.

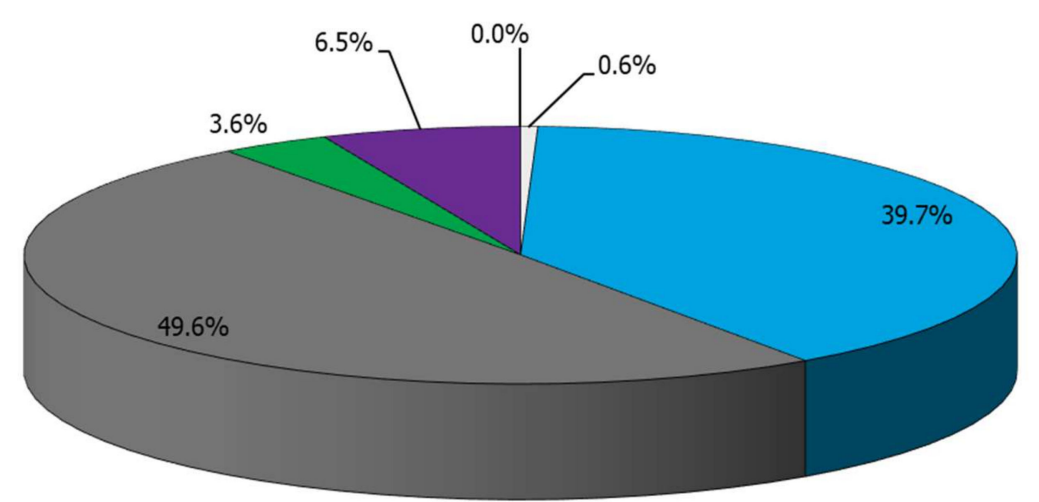

$\square$ Impurities $\square$ Stone $\square$ Concrete $\square$ Ceramic Materials $\square$ Bituminous Materials

Figure 2. Composition of recycled aggregate (RCA) in weight.

Table 2. Characterization of the recycled aggregate (RCA).

\begin{tabular}{cccc}
\hline & & & RCA Fraction \\
\hline Test & Standard & PG-3 & $\mathbf{0 / 4 0}$ \\
\hline LA $(\%)$ & EN-1097-2 & $<25$ & 34 \\
WA $(\%)$ & EN-1097-6 & - & 6.1 \\
FP $(\%)$ & EN-933-5 & 100 & 100 \\
$\rho\left(\mathrm{g} / \mathrm{cm}^{3}\right)$ & EN-1097-6 & - & 2.63 \\
SE $(\%)$ & EN-933-8 & $>50$ & 67 \\
Flakiness index $(\%)$ & EN-933-3 & $<35$ & 34 \\
\hline
\end{tabular}

\subsubsection{Filler}

The filler used in all types of mixtures was Portland cement. The Blaine surface area was $3350 \mathrm{~cm}^{2} / \mathrm{g}$ and the specific gravity was $3.12 \mathrm{~g} / \mathrm{cm}^{3}$.

\subsubsection{Asphalt Binder}

The asphalt used was a conventional 50/70 penetration grade with a penetration grading of $69 \times 10^{-1} \mathrm{~mm}$ and a softening point with the ring and ball method equal to $48.5^{\circ} \mathrm{C}$. Pfeiffer's penetration index had a value of -0.8 with a density of $1.03 \mathrm{~g} / \mathrm{cm}^{3}$. It was confirmed that the asphalt complied with all the Spanish specifications.

\subsection{Methods}

\subsubsection{Manufacturing of the Samples}

The AC22 base 50/70 G aggregate gradation was chosen according to the gradation limits established by PG-3 [12], as shown in Figure 3. 


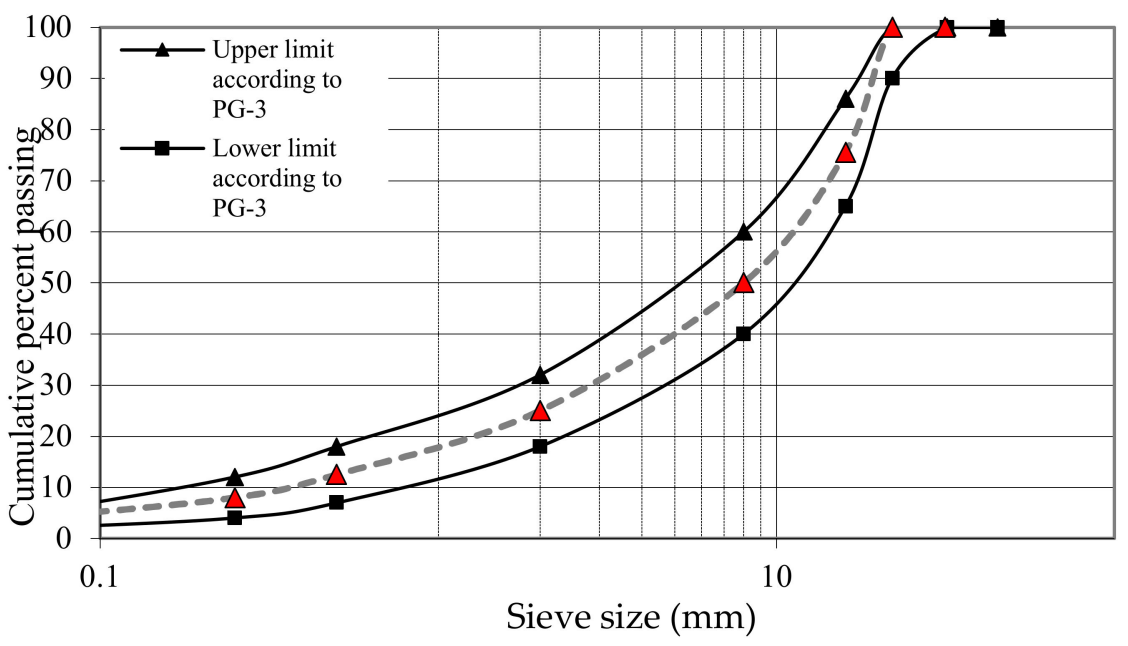

Figure 3. Gradation curve of AC-22 base G.

Marshall specimens were manufactured and compacted $(101.5 \mathrm{~mm}$ in diameter, 63.5 high and 75 blows on each side) at $170{ }^{\circ} \mathrm{C}$. They manufactured 3 series of 2 samples in each one, with bitumen contents of 3.0\%, 3.5\% and 4.0\% (L). Additionally, in each series was employed 4 different percentages of recycled aggregates in the coarse fractions: $0 \%$ (control), 5\%, 10\%, 20\% and 30\% (RCA). In addition, the Marshall specimens were cured in an oven at $170{ }^{\circ} \mathrm{C}$ for 0,2 and $4 \mathrm{~h}(\mathrm{t})$ before compaction. In this way, 90 samples were manufactured in order to carry out the resilient modulus test.

\subsubsection{Stiffness}

Stiffness was evaluated at the testing temperatures of 0,10 and $20^{\circ} \mathrm{C}$ by means of resilient modulus using the indirect tensile stiffness modulus (ITSM) in accordance with the standard UNE-EN-12697-26 Annex C [13].

A Cooper NU 14 tester was used to measure the ITSM. Using Equation (1), the resilient modulus can be determined as:

$$
M_{R}=\frac{F \cdot(v+0.27)}{z \cdot h}
$$

where $M_{R}$ is the resilient modulus (MPa), $F$ is the maximum applied load (N), $z$ is the horizontal deformation (mm), $h$ is the sample thickness $(\mathrm{mm})$ and $v$ is the Poisson's ratio (the value of 0.35 was assumed for the HMA mixes for all the test temperatures). The resilient modulus jig test with the specimen is shown in Figure 4.

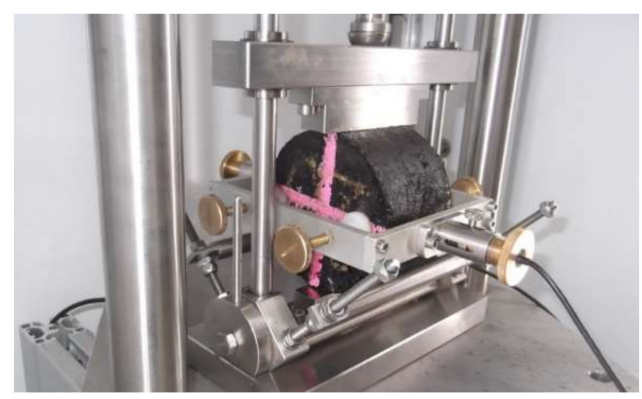

Figure 4. Resilient modulus test equipment.

The maximum load was selected to achieve a maximum horizontal strain of $0.005 \%$ of the specimen diameter. The rise time was $124 \pm 4 \mathrm{~ms}$. 


\subsubsection{Response Surface Methodology}

Response surface methodology (RSM) is useful for analyzing situations where the response is conditioned by several variables, as described in Equation (2) [21]

$$
y=\beta_{0}+\sum_{j=1}^{k} \beta_{j} x_{j}+\sum_{j=1}^{k} \beta_{j j} x_{j}^{2}+\sum_{i=1} \sum_{j>1}^{k} \beta_{i j} x_{i} x_{j}+\beta_{i j l} x_{i} x_{j} x_{l}
$$

where $y$ is the response, $x_{\mathrm{j}}$ are the factors, $\beta_{j}, \beta_{i j}$ and $\beta_{j j}$ are the regression coefficients of factors, interactions and quadratic terms, respectively, and $k$ is the number of the variables or factors included in the factorial design. The quality of the regression was evaluated by determining the coefficient of determination, $\mathrm{R}^{2}$. In addition, the ANOVA of the regression model was also computed. Curing time of the sample $(t)$, temperature of the samples cure $(T)$, percentage of recycled aggregate (RCA) and percentage of bitumen (L) were chosen as independent factors for this study. In order to carry out an unbiased RSM, the variables must be coded from their original values. Table 3 shows the coded values as mean subtracted from the original ones and scaled by their half range.

Table 3. Variables coded levels.

\begin{tabular}{cccc}
\hline Factor & $x_{\boldsymbol{i}}$ & Original Value & Code Level \\
\hline \multirow{3}{*}{$\mathrm{t}$} & $x_{1}$ & $0 \mathrm{~h}$ & -1 \\
& & $4 \mathrm{~h}$ & 0 \\
& & $0{ }^{\circ} \mathrm{C}$ & +1 \\
\hline \multirow{2}{*}{$\mathrm{T}$} & $x_{2}$ & $10^{\circ} \mathrm{C}$ & -1 \\
& & $20^{\circ} \mathrm{C}$ & 0 \\
& & $0 \%$ & +1 \\
\hline \multirow{2}{*}{$\mathrm{RCA}$} & $x_{3}$ & $10 \%$ & $-13 / 15$ \\
& & $20 \%$ & $-8 / 15$ \\
& & $30 \%$ & $-3 / 15$ \\
& & $3.5 \%$ & $+7 / 15$ \\
& & $4 \%$ & $+17 / 15$ \\
\hline \multirow{2}{*}{$\mathrm{L}$} & $x_{4}$ & $4.5 \%$ & -1 \\
& & & 0 \\
\hline
\end{tabular}

\section{Results and Discuss}

Resilient Modulus $\left(M_{R}\right)$

A total of 135 combinations of levels were set in order to obtain the resilient modulus, $M_{R}$, in the following way: three levels of pretreatment time inside the oven at $170{ }^{\circ} \mathrm{C}(0,2$ and $4 \mathrm{~h})$, three levels of temperature $\left(0,10\right.$, and $\left.20^{\circ} \mathrm{C}\right)$, five levels of recycled concrete aggregate percentage $(0 \%, 5 \%, 10 \%$, $20 \%$ and $30 \%$ ) and three levels of binder percentage (3.5\%, $4 \%$ and $4.5 \%)$. Two replicates were tested for each combination to estimate the variance of pure error. The results of $M_{R}$ for each sample are shown in Tables 4 and 5. 
Table 4. Resilient modulus $\left(\mathrm{M}_{\mathrm{R}}\right)$ data.

\begin{tabular}{|c|c|c|c|c|c|c|c|c|c|c|}
\hline & & \multicolumn{9}{|c|}{ Temperature } \\
\hline & & \multicolumn{3}{|c|}{$0^{\circ} \mathrm{C}$} & \multicolumn{3}{|c|}{$10^{\circ} \mathrm{C}$} & \multicolumn{3}{|c|}{$20^{\circ} \mathrm{C}$} \\
\hline & & \multicolumn{9}{|c|}{ Binder } \\
\hline & & $3.5 \%$ & $4 \%$ & $4.5 \%$ & $3.5 \%$ & $4 \%$ & $4.5 \%$ & $3.5 \%$ & $4 \%$ & $4.5 \%$ \\
\hline \multirow[t]{2}{*}{$\mathrm{t}(\mathrm{h})$} & \multicolumn{10}{|c|}{ Resilient Modulus (MPa) } \\
\hline & \multicolumn{10}{|c|}{ RCA 0\% (Control) } \\
\hline \multirow{2}{*}{0} & sample 1 & $24,394.0$ & $23,616.0$ & $23,213.0$ & $15,932.0$ & $13,259.0$ & $12,938.0$ & 5214.0 & 5281.0 & 4879.0 \\
\hline & sample 2 & $20,144.0$ & $22,515.0$ & $22,120.0$ & $12,761.0$ & $10,607.2$ & $12,665.0$ & 4634.0 & 5338.0 & 4828.0 \\
\hline \multirow{2}{*}{2} & sample 1 & $20,564.0$ & $24,496.0$ & $24,107.0$ & $13,913.0$ & $13,491.0$ & $16,979.0$ & 7252.0 & 6436.0 & 7412.0 \\
\hline & sample 2 & $22,443.0$ & $23,852.0$ & $26,186.0$ & $12,913.0$ & $13,809.0$ & $16,668.0$ & 5802.0 & 6034.0 & 7569.0 \\
\hline \multirow{3}{*}{4} & sample 1 & $21,574.0$ & $20,097.0$ & $24,526.0$ & $16,472.0$ & $18,186.0$ & $16,611.0$ & 9515.0 & $10,694.0$ & 8747.0 \\
\hline & sample 2 & $19,122.0$ & $19,922.0$ & $24,393.0$ & $13,787.0$ & $14,548.8$ & $16,379.0$ & 7612.0 & 9596.0 & 6997.6 \\
\hline & \multicolumn{10}{|c|}{ RCA 5\% } \\
\hline \multirow{2}{*}{0} & sample 1 & $20,021.0$ & $21,268.0$ & $22,417.0$ & $10,302.0$ & $12,224.0$ & $12,902.0$ & 3926.0 & 4673.0 & 4780.0 \\
\hline & sample 2 & $19,896.0$ & $20,654.0$ & $22,754.0$ & $10,975.0$ & $11,874.0$ & $12,816.0$ & 3647.0 & 4297.0 & 4719.0 \\
\hline \multirow[b]{2}{*}{2} & sample 1 & $22,131.0$ & $23,579.0$ & $21,669.0$ & $12,756.0$ & $14,500.0$ & $11,617.0$ & 6402.0 & 6394.0 & 5157.0 \\
\hline & sample 2 & $23,145.0$ & $22,817.0$ & $20,556.0$ & $13,370.0$ & $14,427.0$ & $11,921.0$ & 6394.0 & 6593.0 & 5642.0 \\
\hline \multirow{3}{*}{4} & sample 1 & $26,774.0$ & $25,614.0$ & $23,808.0$ & $19,155.0$ & $18,946.0$ & $14,679.0$ & $11,692.0$ & $10,182.0$ & 8195.0 \\
\hline & sample 2 & $21,609.0$ & $27,637.0$ & $23,646.0$ & $19,124.0$ & $17,017.0$ & $14,064.0$ & $11,564.0$ & 8473.6 & 7660.0 \\
\hline & \multicolumn{10}{|c|}{ RCA $10 \%$} \\
\hline \multirow{2}{*}{0} & sample 1 & $19,995.0$ & $21,540.0$ & $22,661.0$ & $10,550.0$ & $11,570.0$ & $15,358.0$ & 4308.0 & 4694.0 & 5495.0 \\
\hline & sample 2 & $19,177.0$ & $21,116.0$ & $20,702.0$ & $10,248.0$ & $11,561.0$ & $12,951.0$ & 4027.0 & 4603.0 & 5285.0 \\
\hline \multirow{2}{*}{2} & sample 1 & $22,345.0$ & $25,288.0$ & $22,395.0$ & $14,593.0$ & $15,417.0$ & $14,722.0$ & 6416.0 & 6872.0 & 6583.0 \\
\hline & sample 2 & $20,060.0$ & $22,082.0$ & $22,847.0$ & $12,174.0$ & $14,660.0$ & $13,704.0$ & 6021.0 & 6899.0 & 6192.0 \\
\hline \multirow{2}{*}{4} & sample 1 & $23,416.0$ & $25,694.0$ & $22,981.0$ & $16,128.0$ & $16,879.0$ & $17,863.0$ & $10,014.0$ & 8052.0 & 9603.0 \\
\hline & sample 2 & $21,351.0$ & $24,291.0$ & $24,378.0$ & $16,478.0$ & $16,615.0$ & $17,516.0$ & 9874.0 & 6441.6 & 9514.0 \\
\hline
\end{tabular}


Table 5. Resilient modulus $\left(\mathrm{M}_{\mathrm{R}}\right)$ data.

\begin{tabular}{|c|c|c|c|c|c|c|c|c|c|c|}
\hline & & \multicolumn{9}{|c|}{ Temperature } \\
\hline & & \multicolumn{3}{|c|}{$0^{\circ} \mathrm{C}$} & \multicolumn{3}{|c|}{$10^{\circ} \mathrm{C}$} & \multicolumn{3}{|c|}{$20{ }^{\circ} \mathrm{C}$} \\
\hline & & \multicolumn{9}{|c|}{ Binder } \\
\hline & & $3.5 \%$ & $4 \%$ & $4.5 \%$ & $3.5 \%$ & $4 \%$ & $4.5 \%$ & $3.5 \%$ & $4 \%$ & $4.5 \%$ \\
\hline \multirow[t]{2}{*}{$\mathrm{t}(\mathrm{h})$} & \multicolumn{10}{|c|}{ Resilient Modulus (MPa) } \\
\hline & \multicolumn{10}{|c|}{ RCA $20 \%$} \\
\hline \multirow{2}{*}{0} & sample 1 & $20,398.0$ & $21,603.0$ & $20,706.0$ & $12,176.0$ & $11,972.0$ & $11,961.0$ & 5722.0 & 5164.0 & 4719.0 \\
\hline & sample 2 & $20,432.0$ & $21,655.0$ & $21,663.0$ & $11,601.0$ & $11,749.0$ & $12,379.0$ & 5537.0 & 4717.0 & 4916.0 \\
\hline \multirow{2}{*}{2} & sample 1 & $23,229.0$ & $20,612.0$ & $25,917.0$ & $12,625.0$ & $13,425.0$ & $14,925.0$ & 5727.0 & 5477.0 & 6762.0 \\
\hline & sample 2 & $19,042.0$ & $20,745.0$ & $25,708.0$ & $12,130.0$ & $12,056.0$ & $15,402.0$ & 5167.0 & 5664.0 & 6878.0 \\
\hline \multirow{3}{*}{4} & sample 1 & $20,964.0$ & $21,830.0$ & $25,537.0$ & $15,793.0$ & $16,584.0$ & $16,863.0$ & $10,015.0$ & 7660.0 & 9277.0 \\
\hline & sample 2 & $20,659.0$ & $21,498.0$ & $25,949.0$ & $16,083.0$ & $17,992.0$ & $16,487.0$ & 9703.0 & 7317.0 & 8765.0 \\
\hline & \multicolumn{10}{|c|}{ RCA 30\% } \\
\hline \multirow{2}{*}{0} & sample 1 & $21,039.0$ & $22,633.0$ & $22,110.0$ & $11,232.0$ & $11,352.0$ & $13,745.0$ & 6006.0 & 4497.0 & 5036.0 \\
\hline & sample 2 & $19,588.0$ & $19,132.0$ & $22,588.0$ & $11,182.0$ & $10,384.0$ & $13,324.0$ & 5320.0 & 4037.0 & 5137.0 \\
\hline \multirow{2}{*}{2} & sample 1 & $20,604.0$ & $19,502.0$ & $24,873.0$ & $13,294.0$ & $15,891.0$ & $15,523.0$ & 7044.0 & 6390.0 & 7368.0 \\
\hline & sample 2 & $19,600.0$ & $20,557.0$ & $23,415.0$ & $13,781.0$ & $15,155.0$ & $15,891.0$ & 7182.0 & 6140.0 & 7368.0 \\
\hline \multirow{2}{*}{4} & sample 1 & $23,312.0$ & $21,594.0$ & $21,525.0$ & $17,048.0$ & $15,378.0$ & $14,201.0$ & $12,941.0$ & 9239.0 & 7622.0 \\
\hline & sample 2 & $21,746.0$ & $21,151.0$ & $21,157.0$ & $16,648.0$ & $14,841.0$ & $13,428.0$ & $10,453.0$ & 8836.0 & 7793.0 \\
\hline
\end{tabular}


Table 6 shows the analysis of variance of the least squares problem for the full regression model presented in Equation (2). A factorial design of experiments with at least three levels allows the prediction of coefficients for non-linear models with pure quadratic terms. The $p$-value related to the statistics $F_{0}$ of the regression is significant, which means that there is at least one $\beta_{j}$ that is different from zero. In addition, $R^{2}$ is 0.96 , which indicates that only $4 \%$ of the total response variance is due to unexplained reasons. However, it is also concluded that the lack of fit test proves that there are missing terms important to the model.

Table 6. Analysis of variance and lack of fit test for a full second order model.

\begin{tabular}{cccccc}
\hline Source of Variation & Sum of Squares & Degrees of Freedom & Mean Square & F0 & $p$-Value \\
\hline Regression & $1.14 \times 10^{10}$ & 14 & $8.16 \times 10^{8}$ & $4.16 \times 10^{2}$ & $<0.0001$ \\
Residual & $5.00 \times 10^{8}$ & 255 & $1.96 \times 10^{6}$ & & \\
Lack of fit & $3.85 \times 10^{8}$ & 120 & $3.21 \times 10^{6}$ & 3.77 & $<0.0001$ \\
Pure error & $1.15 \times 10^{8}$ & 135 & $8.50 \times 10^{5}$ & & \\
Total & $1.19 \times 10^{10}$ & 269 & $4.43 \times 10^{7}$ & & \\
\hline
\end{tabular}

In Figure 5, a plot of residuals versus the predicted values of the resilient modulus is presented. There is an indication of an outward-opening funnel in the plot, implying possible inequality of variance.

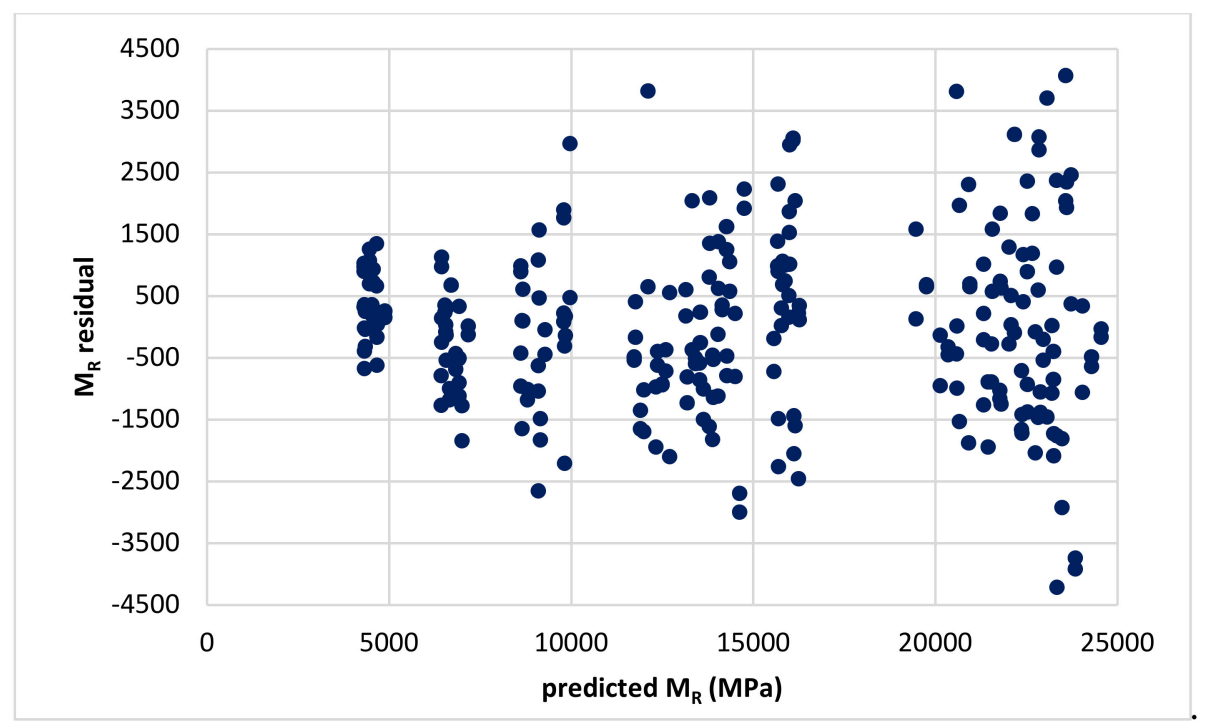

Figure 5. Plot of residuals versus predicted resilient modulus $\left(\mathrm{M}_{\mathrm{R}}\right)$ for a full second order model.

This inequality of the response variance was an indication to the authors that a transformation in the response is required. A log transformation was proposed to stabilize the variance of the response according to the general equation:

$$
\ln (y)=\beta_{0}+\sum_{j=1}^{k} \beta_{j} x_{j}+\sum_{j=1}^{k} \beta_{j j} x_{j}^{2}+\sum_{i=1} \sum_{j>1}^{k} \beta_{i j} x_{i} x_{j}
$$

The scaled estimates and respective tests on individual regression coefficients are presented in Table 7. The $\mathrm{H}_{0}$ stands for the statement that the coefficient is null. The null hypothesis $\mathrm{H}_{0}$ presented in the last column of Table 5 stands for the statement that the coefficient is null, given the remaining are important for the model. In Table 7, "No" means that the null hypothesis must be rejected with a confidence level of $95 \%$ while "yes" means the opposite. 
Table 7. Scaled estimates and $t$-test on individual regression coefficients.

\begin{tabular}{cccccc}
\hline$x_{i}$ & $\beta_{j}$ & Standard Error & $t$-Test & $p$-Value & $\mathbf{H}_{\mathbf{0}}$ \\
\hline independent & 9.52 & 0.02 & 525.4 & 0.0000 & No \\
$x_{1}$ & $1.66 \times 10^{-1}$ & $7.54 \times 10^{-3}$ & 21.98 & $<0.0001$ & No \\
$x_{2}$ & $-6.11 \times 10^{-1}$ & $7.54 \times 10^{-3}$ & -81.06 & $<0.0001$ & No \\
$x_{3}$ & $-1.32 \times 10^{-2}$ & $9.67 \times 10^{-3}$ & -1.37 & 0.1726 & Yes \\
$x_{4}$ & $1.82 \times 10^{-2}$ & $7.54 \times 10^{-3}$ & 2.42 & 0.0163 & No \\
$x_{1} x_{2}$ & $1.40 \times 10^{-1}$ & $9.24 \times 10^{-3}$ & 15.17 & $<0.0001$ & No \\
$x_{1} x_{3}$ & $-4.63 \times 10^{-3}$ & $1.05 \times 10^{-2}$ & -0.44 & 0.6596 & Yes \\
$x_{1} x_{4}$ & $-3.46 \times 10^{-2}$ & $9.24 \times 10^{-3}$ & -3.75 & 0.0002 & No \\
$x_{2} x_{3}$ & $2.30 \times 10^{-2}$ & $1.05 \times 10^{-2}$ & 2.19 & 0.0296 & No \\
$x_{2} \cdot x_{4}$ & $-3.07 \times 10^{-2}$ & $9.24 \times 10^{-3}$ & -3.33 & 0.0010 & No \\
$x_{3} x_{4}$ & $-5.72 \times 10^{-3}$ & $1.05 \times 10^{-2}$ & -0.54 & 0.5866 & Yes \\
$x_{1}^{2}$ & $5.97 \times 10^{-3}$ & $1.31 \times 10^{-2}$ & 0.46 & 0.6479 & Yes \\
$x_{2}^{2}$ & $-1.53 \times 10^{-1}$ & $1.31 \times 10^{-2}$ & -11.71 & $<0.0001$ & No \\
$x_{3}^{2}$ & $1.97 \times 10^{-2}$ & $1.54 \times 10^{-2}$ & 1.28 & 0.2023 & Yes \\
$x_{4}^{2}$ & $1.55 \times 10^{-2}$ & $1.31 \times 10^{-2}$ & 1.19 & 0.2368 & Yes \\
\hline
\end{tabular}

Excluding the RCA effect and its interactions as well as all pure quadratic terms but temperature, results in the following expression:

$$
\ln \left(M_{R}\right)=9.55+0.166 x_{1}-0.611 x_{2}+0.018 x_{4}+0.140 x_{1} x_{2}-0.035 x_{1} x_{4}-0.031 x_{2} x_{4}-0.15 x_{2}^{2}
$$

By the analysis of variance and the lack of fit test presented in Table 8, it can be concluded that Equation (4) models the data adequately well and no potential terms are missing in the model.

Table 8. Analysis of variance and lack of fit test for the incomplete log transformation model.

\begin{tabular}{cccccc}
\hline Source of Variation & Sum of Squares & Degrees of Freedom & Mean Square & $\mathbf{F}_{\mathbf{0}}$ & $p$-Value \\
\hline Regression & 76.3 & 7 & 10.9 & $1.06 \times 10^{3}$ & $<0.0001$ \\
Residual & 2.71 & 262 & 0.01 & & \\
Lack of fit & 0.30 & 19 & 0.016 & 1.60 & 0.0569 \\
Pure error & 2.41 & 243 & 0.010 & & \\
Total & 79.01 & 269 & 0.294 & & \\
\hline
\end{tabular}

Furthermore, the $\mathrm{R}^{2}$ is 0.97 showing that only $3 \%$ of the response variance is due to random uncontrolled factors. The model, Equation (4), predicts an increase in the resilient modulus by increasing time of the pretreatment at higher temperatures. Conversely, the cure time influence is harmful at lower levels of temperature, revealing a minimum. This is due to the greater absorption of bitumen in the mixture when the sample stays in the oven long enough.

On the other hand, a temperature increase causes a significant decrease in the resilient modulus. This is an expected behavior since it is a known fact that the higher the temperature, the lower the stiffness of a material. At higher temperatures, the atomic vibration increases and with it the distance between the molecules that make up the material, thus the material expands because of the movement and the collisions between the molecules, and therefore the free volume becomes larger.

The binder has a weak influence in the resilient modulus, changing from positive to negative effect when temperature goes from low to high levels. The same trend is observed when cure time goes from low to high levels.

Figure 6 shows the response surface model as well as the experimental data. The asterisk means that the variables are represented by their coded values. A monotonic trend may be visualized in graphs (a) and (b). However, in graph (c), a saddle point can be identified. This is a result of the combined effect of temperature's quadratic effect and the interaction between temperature and cure time. 


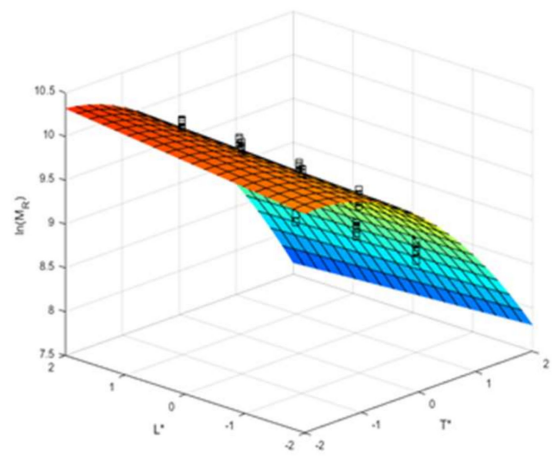

(a)

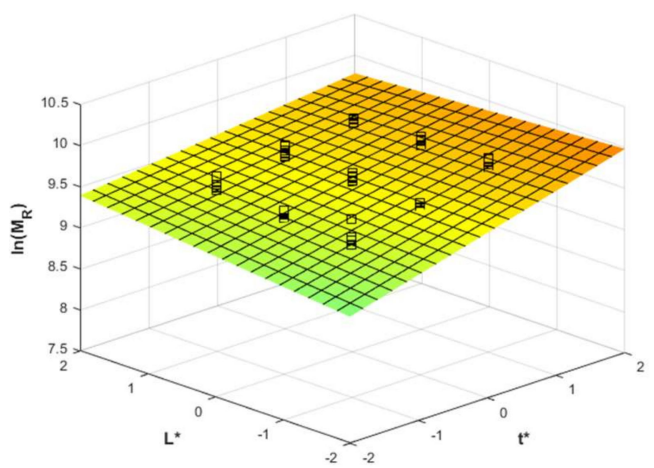

(b)

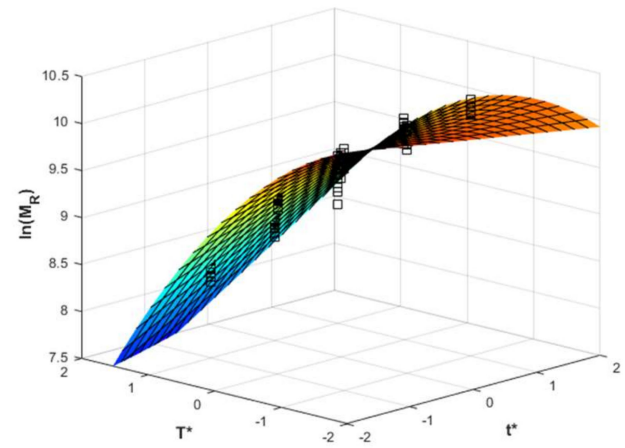

(c)

Figure 6. Response surface of $\ln \left(\mathrm{M}_{\mathrm{R}}\right)$ as function of two scaled predictors at the center of the excluded one: (a) temperature $\left(\mathrm{T}^{*}\right)$ and binder content $\left(\mathrm{L}^{*}\right) ;(\mathbf{b})$ cure time $\left(\mathrm{t}^{*}\right)$ and binder content $\left(\mathrm{L}^{*}\right) ;(\mathbf{c})$ cure time $\left(\mathrm{t}^{*}\right)$ and temperature $\left(\mathrm{T}^{*}\right)$. The experimental data are represented as square markers.

To add more clarity to the discussed above, Figure 7 shows the contour plots of the significant coded variables studied. In graph (c), a single stationary point can be pointed out at the coordinates $(1.6 ;-1.2)$, approximately corresponding to a predicted resilient modulus of more than $2.3 \times 10^{4} \mathrm{MPa}$. This saddle point is the combination of a maximum along the approximate direction of temperature axis and a minimum in the orthogonal direction. 


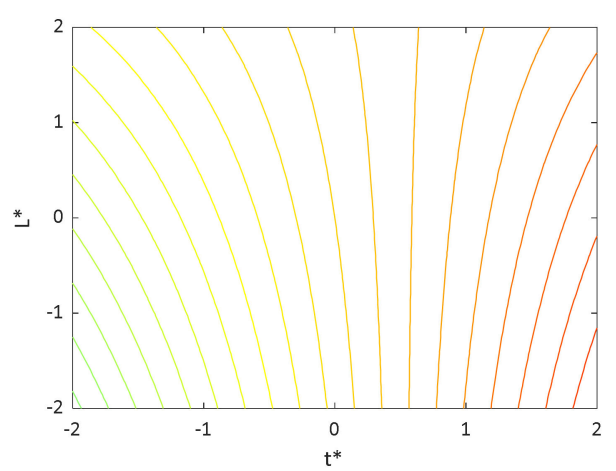

(a)

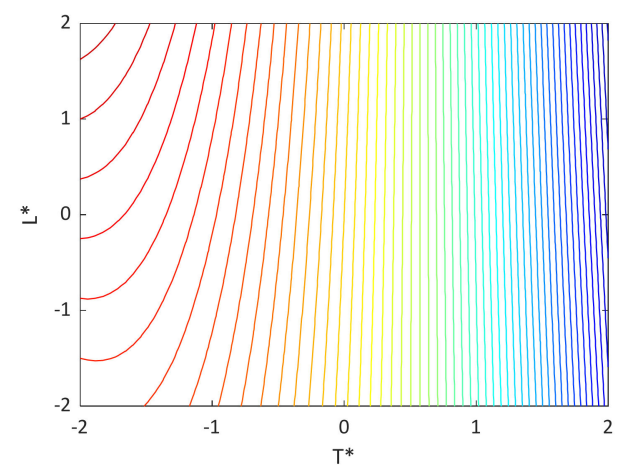

(b)

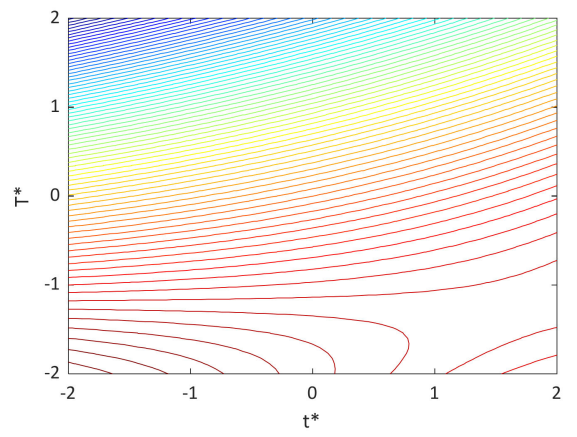

(c)

Figure 7. Contour plots of the $\ln \left(\mathrm{M}_{\mathrm{R}}\right)$ at the plane of two scaled predictor coordinates at the center of the excluded third one: (a) temperature $\left(\mathrm{T}^{*}\right)$ and binder content $\left(\mathrm{L}^{*}\right) ;(\mathbf{b})$ cure time $\left(\mathrm{t}^{*}\right)$ and binder content $\left(\mathrm{L}^{*}\right) ;(\mathbf{c})$ cure time $\left(\mathrm{t}^{*}\right)$ and temperature $\left(\mathrm{T}^{*}\right)$.

\section{Conclusions}

The influence of the pretreatment time, temperature of the test, percentage of recycled aggregate and percentage of binder on the value of the resilient modulus has been studied by response surface methodology (RSM). Hornfels and construction and demolition waste were used as natural and recycled aggregates, respectively. Marshall samples type AC22 base 50/70 G were tested in a Cooper NU 14 tester.

According to RSM model, temperature is the most influential parameter. As the temperature increases, the rigidity of the mixture decreases. On the other hand, pretreatment time is a positive factor in increasing the resilient modulus at high temperatures. Samples that were in the oven longer behaved more rigidly. However, at low temperatures, the cure time seems to be harmful to the stiffness of the material.

It was observed that the percentage of the binder has a slight influence on the resilient modulus, with the range of values of cure time and temperature depending on the direction of its influence.

This work shows that the percentage of recycled aggregate, in the range between $0 \%$ and $30 \%$, does not influence the rigidity of the HMA.

The results obtained show that hot mixes made with $\mathrm{CD}$ are not suitable for use as a wearing course. Therefore, they cannot be used as new surfaces in road pavement rehabilitation.

This research studies only technical aspects of hot asphalt mixes with recycled aggregates. No market study has been carried out to find out the commercialization possibilities. However, it can be stated that this type of asphalt mix is economically profitable, as shown by the results of a project carried out by a consortium of several leading companies in the Spanish sector [22].

The present research should be complemented by the study of resistance to permanent deformation, using a uniaxial compression test and a rutting test. 
Author Contributions: Both I.P. and A.R.P. designed the laboratory study, L.M.S. and J.J.G. analyzed the data and all authors wrote and revised the article. All authors have read and agreed to the published version of the manuscript.

Funding: This research received no external funding.

Acknowledgments: The authors gratefully acknowledge financial support of this research work through Fundação para a Ciência e Tecnologia (FCT)-UIDB/04730/2020 project and the scholarship awarded in the 2018-2019 academic year by the IACOBUS program.

Conflicts of Interest: The authors declare no conflict of interest.

\section{References}

1. European Commission. Closing the Loop-An EU Action Plan for the Circular Economy. COM (2015) 614 Final. 2015. Available online: https:/eur-lex.europa.eu/resource.html?uri=cellar:8a8ef5e8-99a0-11e5-b3b701aa75ed71a1.0012.02/DOC_1\&format=PDF (accessed on 13 October 2020).

2. Pereira, P.A.; Oliveira, J.; Santos, L.P. Mechanical Characterisation of Hot Mix Recycled Materials. Int. J. Pavement Eng. 2004, 5, 211-220. [CrossRef]

3. Pérez, I.P.; Pasandin, A.R.; Gallego, J. Stripping in hot mix asphalt produced by aggregates from construction and demolition waste. Waste Manag. Res. 2012, 30, 3-11. [CrossRef] [PubMed]

4. Mah, C.M.; Fujiwara, T.; Ho, C.S. Environmental impacts of construction and demolition waste management alternatives. Chem. Eng. Trans. 2018, 63, 343-348.

5. Chappat, M.; Bilal, J. Energy "Consumption and Greenhouse Gas Emissions". Sustainable Developmentethe Environmental Road of the Future; Colas Group: Paris, France, 2003.

6. Lee, N.; Chou, C.-P.; Chen, K.-Y. Benefits in energy savings and $\mathrm{CO}_{2}$ reduction by using reclaimed asphalt pavement. In Proceedings of the Transportation Research Board 91st Annual Meeting, Washington, DC, USA, 22-26 January 2012.

7. Aurangzeb, Q.; Al-Qadi, I.; Hasan, M.; Yang, R. Hybrid life cycle assessment for asphalt mixtures with high RAP content. Resour. Conserv. Recycl. 2014, 83, 77-86. [CrossRef]

8. Saberian, M.; Li, J.; Nguyen, B.T.; Setunge, S. Estimating the resilient modulus of crushed recycled pavement materials containing crumb rubber using the Clegg impact value. Resour. Conserv. Recycl. 2019, 141, 301-307. [CrossRef]

9. Aljassar, A.H.; Al-Fadala, K.B.; Ali, M.A. Recycling building demolition waste in hot-mix asphalt concrete: A case study in Kuwait. J. Mater. Cycles Waste Manag. 2005, 7, 112-115. [CrossRef]

10. Paranavithana, S.; Mohajerani, A. Effects of recycled concrete aggregates on properties of asphalt concrete. Resour. Conserv. Recycl. 2006, 48, 1-12. [CrossRef]

11. Pérez, I.P.; Pasandin, A.R.; Medina, L. Hot mix asphalt using C\&D waste as coarse aggregates. Mater. Des. 2012, 36, 840-846. [CrossRef]

12. Mamlouk, M.; Sarofim, R.T. Modulus of asphalt mixtures-an unresolved dilemma. Transp. Res. Rec. 1988, 1171, 193-198.

13. AENOR. Asociación Española de Normalización y Certificación. UNE-EN 12697-23 “Bituminous Mixtures; Test Methods for Hot Mix Asphalt; Stiffness: Madrid, Spain, 2006.

14. Galan, J.J.; Silva, L.M.S.; Pérez, I.P.; Pasandin, A.R. Mechanical Behavior of Hot-Mix Asphalt Made with Recycled Concrete Aggregates from Construction and Demolition Waste: A Design of Experiments Approach. Sustainability 2019, 11, 3730. [CrossRef]

15. Huang, B.; Shu, X.; Tang, Y. Comparison of Semi-Circular Bending and Indirect Tensile Strength Tests for HMA Mixtures. Soil Dyn. Symp. Profr. Richard D. Woods 2005, 1-12. [CrossRef]

16. Haghshenas, H.; Khodaii, A.; Khedmati, M.; Tapkın, S. A mathematical model for predicting stripping potential of Hot Mix Asphalt. Constr. Build. Mater. 2015, 75, 488-495. [CrossRef]

17. Chávez-Valencia, L.; Manzano-Ramírez, A.; Luna-Bárcenas, G.; Alonso-Guzmán, E. Modelling of the performance of asphalt pavement using response surface methodology. Build. Environ. 2005, 40, 1140-1149. [CrossRef]

18. Nassar, A.I.; Thom, N.; Parry, T. Optimizing the mix design of cold bitumen emulsion mixtures using response surface methodology. Constr. Build. Mater. 2016, 104, 216-229. [CrossRef] 
19. Hamzah, M.O.; Teh, S.Y.; Golchin, B.; Voskuilen, J. Use of imaging technique and direct tensile test to evaluate moisture damage properties of warm mix asphalt using response surface method. Constr. Build. Mater. 2017, 132, 323-334. [CrossRef]

20. Dirección General de Carreteras. Pliego de Prescripciones Técnicas Generales Para Obras de Carreteras y Puentes PG-3; Ediciones Liteam: Madrid, Spain, 2002.

21. Montgomery, D. Design and Analysis of Experiments, 8th ed.; Joh Wiley and Sons: London, UK, 2013; pp. 478-496.

22. Available online: https://www.zicla.com/en/project/concrete-recycled-aggregates/ (accessed on 1 September 2020).

Publisher's Note: MDPI stays neutral with regard to jurisdictional claims in published maps and institutional affiliations.

(C) 2020 by the authors. Licensee MDPI, Basel, Switzerland. This article is an open access article distributed under the terms and conditions of the Creative Commons Attribution (CC BY) license (http://creativecommons.org/licenses/by/4.0/). 